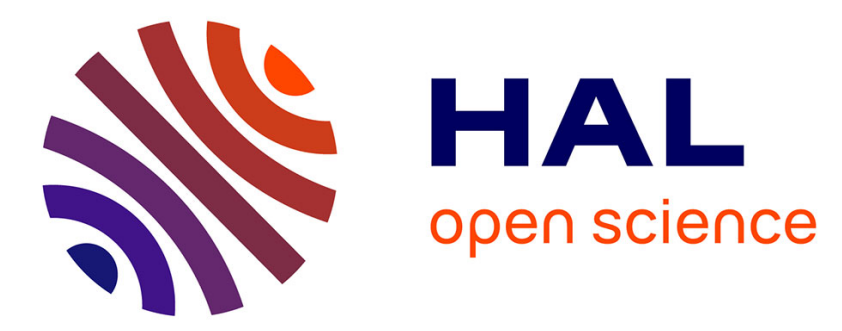

\title{
In-Cell EPR: Progress towards Structural Studies Inside Cells
}

\author{
Alessio Bonucci, Olivier Ouari, Bruno Guigliarelli, Valérie Belle, Elisabetta \\ Mileo
}

\section{> To cite this version:}

Alessio Bonucci, Olivier Ouari, Bruno Guigliarelli, Valérie Belle, Elisabetta Mileo. In-Cell EPR: Progress towards Structural Studies Inside Cells. ChemBioChem, 2020, 21 (4), pp.451-460. 10.1002/cbic.201900291 . hal-03001306

\section{HAL Id: hal-03001306 https://hal.science/hal-03001306}

Submitted on 12 Nov 2020

HAL is a multi-disciplinary open access archive for the deposit and dissemination of scientific research documents, whether they are published or not. The documents may come from teaching and research institutions in France or abroad, or from public or private research centers.
L'archive ouverte pluridisciplinaire HAL, est destinée au dépôt et à la diffusion de documents scientifiques de niveau recherche, publiés ou non, émanant des établissements d'enseignement et de recherche français ou étrangers, des laboratoires publics ou privés. 


\title{
In-cell EPR: progress towards structural studies inside cells.
}

\author{
Alessio Bonucci, ${ }^{[b]}$ Olivier Ouari, ${ }^{[c]}$ Bruno Guigliarelli, ${ }^{[a]}$ Valérie Belle ${ }^{[a]}$ and Elisabetta Mileo*[a] \\ Abstract: Exploring biomolecules' structure and dynamics in the \\ context of their intracellular environment has become the ultimate \\ challenge for structural biology. As the cellular environment is barely \\ reproducible in vitro, investigation of biomolecules directly inside cells \\ proved its potential in investigating biological macromolecules \\ inside cells. In this review, we provide a description of the in-cell \\ EPR approach. In particular, we report on recent milestones, as \\ well as on the challenges the approach still poses.
}

\begin{abstract}
has attracted a growing interest. Among magnetic resonance approaches, Site-Directed Spin Labeling (SDSL) coupled to Electron Paramagnetic Resonance (EPR) spectroscopy provides competitive and advantageous features to capture protein structure and dynamics inside cells. To date, several in-cell EPR approaches have been successfully applied to both bacterial and eukaryotic cells. In this review, the major advances of in-cell EPR are summarized, as well as the challenges this approach still poses.
\end{abstract}

\section{Introduction}

As Lisa Charlton and Gary Pielak stated some years ago, looking at protein structural dynamics at molecular level in their physiological environment represents the "nirvana" for scientists. ${ }^{[1]}$ The intracellular environment is indeed extremely heterogeneous, complex, and crowded. Exploring biomolecule structure and dynamics, as well as following structural changes and interactions in the intracellular environment, have become the ultimate challenge for structural biology. The viscosity of the cytoplasm, the macromolecular crowding, specific and nonspecific weak interactions, as well as a myriad of potential interactors constitute parameters that can have a huge impact on protein structure, dynamics and protein-partner interaction. ${ }^{[2]}$ As the cellular environment is difficult to reproduce in vitro, investigation of biomolecules directly inside cells has attracted a growing interest in the last few decades. Mass Spectrometry has been successfully employed to probe protein structure and protein-protein interactions in crude lysates, ${ }^{[3]}$ and the rapid improvements of the technique will soon allow in cell studies. ${ }^{[4]}$ Fluorescence-based microscopy has permitted impressive studies of subcellular dynamics, protein-biomolecule interactions and protein aggregation in a physiological setting. ${ }^{[5]}$ Since 2006, efforts in Magnetic Resonance Spectroscopies have enabled important improvements in the study of structural dynamics directly in the cellular context. Liquid state and, more recently, DNP solid state NMR have both been already applied to probe the structure and dynamic features of globular, membrane and disordered proteins, ${ }^{[2,6]}$ as well as nucleic acids in several cell types. ${ }^{[7]}$

Among magnetic resonances approaches, Site-Directed Spin Labeling coupled to Electron Paramagnetic Resonance spectroscopy (SDSL-EPR) has demonstrated to be an accurate and powerful approach to study structural properties of biomolecules, such as soluble and membrane proteins, as well as nucleic acids. ${ }^{[8]}$ SDSL-EPR has been broadly applied in vitro and, since 2010, the increasing number of in-cell studies has

\footnotetext{
[a] Dr. E. Mileo, Pr. B. Guigliarelli, Pr. V. Belle

Aix Marseille Univ, CNRS, Bioénergétique et Ingénierie des

Protéines, IMM, Marseille, France. emileo@imm.cnrs.fr

[b] Dr. A. Bonucci

Magnetic Resonance Center - CERM, University of Florence, Sesto Fiorentino, Italy.

[c] Dr. O. Ouari

Aix Marseille Univ, CNRS, Institut de Chimie Radicalaire, Marseille, France.
}

\section{In vitro and in-cell EPR}

\subsection{In vitro SDSL-EPR}

The SDSL approach is based on the introduction of a paramagnetic label (nitroxide radicals, lanthanide- or trityl-based tags) at a specific position of a protein or a nucleic acid followed by its study by EPR spectroscopy.

By far, the largest family of spin labels in SDSL-EPR is nitroxide radicals, with Gadolinium(III) complexes and Trityl radicals being interesting alternatives. One of the main advantages of nitroxide spin labels is their high sensitivity to the local environment which, in the SDSL-EPR approach, is used to obtain structural and dynamic information on the biomolecule on which the nitroxide is attached. ${ }^{[8 \mathrm{c}, 8 \mathrm{~g}, 9]}$

In the case of nitroxide labels, SDSL-EPR, combined with protein mutagenesis, is based on the selective grafting on cysteine. ${ }^{[10]}$ Even if Cys residues represent the main grafting site, few examples of labeling on tyrosine residues were also reported. ${ }^{[11]}$ The consecutive study of the EPR spectra and their parameters provides detailed information on the local mobility of the grafted label. Spin label dynamics is related to local structural properties of the protein under investigation and can thus be used to follow protein's structural changes ${ }^{[12]}$ and to detect interaction sites in complexes ${ }^{[13]}$ or monitor folding events. ${ }^{[8]}$ This kind of EPR studies is conducted in a continuous wave mode (cw-based EPR) and is carried out in solution. This represents a very interesting feature in the case of cellular studies because it allows the investigation of a biological system in conditions as close as possible to the physiological ones. In the following sections, we will define this approach "solution state EPR". On the other hand, Pulsed Dipolar EPR techniques combined with doubly labeled systems, allow accurate distance measurements between two paramagnetic centers, thus enabling the characterization of the global structure of a biomolecule. ${ }^{[14]}$ Distance measurements by Pulsed Dipolar EPR are based on the dipole-dipole coupling measurements between the unpaired electrons. Commonly, distances between spin centers are measured by applying the Double Electron-Electron Resonance (DEER) sequence, a two-frequencies experiment. The distances that can be investigated lie typically between 1.5 and $8.0 \mathrm{~nm}$ and, by employing perdeuterated proteins, it even is possible to reach $16 \mathrm{~nm} \cdot{ }^{[15]}$ As an alternative to DEER, we can mention pulse sequences working with a single microwave frequency such as RIDME[16] (Relaxation-Induced Dipolar Modulation Enhancement), DCQ ${ }^{[17]}$ (Double Quantum Coherence) and SIFTER ${ }^{[18]}$ (Single-Frequency TEchnique for Refocusing Dipolar Couplings). Pulsed Dipolar experiments are usually carried out at cryogenic temperature (below $80 \mathrm{~K}$ ) due to fast electron transverse relaxation of paramagnetic centers at room temperature. In contrast to cw-based EPR, the samples are in a frozen glassy state.

Methods to label nucleic acids are also well established and can be successfully used to probe DNA and RNA conformational flexibility and dynamics. ${ }^{80,19]}$ In the case of nucleic acids, the nitroxide label can be incorporated during the chemical synthesis of the nucleic acid or can be introduced after synthesis of the 
oligonucleotide, on a modified nucleotide containing a uniquely reactive functional group. After proper labeling, the paramagnetic nucleic acid can be followed by both "solution-state" and Pulsed Dipolar EPR approaches.

A recently reported labeling strategy for nucleic acids is based on noncovalent interactions (hydrogen bonding, ionic- and Van der Waals interactions) between the spin label and the nucleic acids. The 'non-covalent' labeling is very interesting because is free from several drawbacks that affect the 'covalent' labeling approach, such as the reduction of the nitroxide during its exposure to the reagents in the course of the nucleotide synthesis or the non-specific conjugation of the nitroxide with other functional groups (as in the case of isocyanates, for example). ${ }^{[20]}$

More recently, lanthanide tags based on the complexation of $\mathrm{Gd}^{3+}$ ions have shown to be promising probes for distance measurements on proteins. ${ }^{[14 a, 21]}$ Transition metals, such as $\mathrm{Cu}^{2+}, \mathrm{Mn}^{2+}, \mathrm{Mo}^{5+}$ and $\mathrm{Fe}^{3+}$ have also been shown to be interesting paramagnetic centers in protein studies. ${ }^{[22]}$

The availability of different spin labels, mainly characterized by different spectral features, allows orthogonal spin labeling, in which the use of two non-identical spin labels represents an attractive strategy for studying biomolecule complexes. ${ }^{[23]}$

\subsection{In-cell EPR}

EPR studies in cellular contexts date back to more than 60 years. The light-induced paramagnetism of chloroplast observed by Commoner et al. ${ }^{[24]}$ or the investigation of nitroxide behavior in cells, tissues and whole animals for EPR and magnetic resonance imaging (EPRI and $\mathrm{MRI}$, respectively) are some examples. ${ }^{[25]}$ However, in the past decade, the flowering of structural studies of biological macromolecules in their native environment was associated with the introduction of the concept of "in-cell spectroscopies", such as in-cell FRET, in-cell NMR and in-cell EPR. Thus, in this paper we adopted the "in-cell" definition for structural studies of proteins or nucleic acids, inside cells.

Since the first in-cell EPR work, reported in $2010,{ }^{[26]}$ several studies have highlighted the advantageous features and the potential of SDSL-EPR in studying protein and nucleic acid structural dynamics inside cells. Besides the fact that EPR spectroscopy is a non-destructive technique that can provide structural details and conformational exchange details over a wide range of temperature and timescales ( $\mathrm{ns}$ to $\mathrm{ms}$ ), SDSLEPR is characterized by a high sensitivity (few $\mu \mathrm{L}$ at $\sim 30-50 \mu \mathrm{M}$ concentration), negligible background interference and no molecular size limit of the biomolecule or complex under study.

In order to study biological macromolecules inside cells by EPR spectroscopy, experiments are generally conducted by labeling the system of interest prior to its delivery inside cells.

In 2010, Tochio and Shirakawa ${ }^{[19]}$ measured inter-spin distances in two variants of the human ubiquitin protein, labeled with a commercially available nitroxide (1, Figure 1 ), and then microinjected inside Xenopus laevis oocytes. In order to perform DEER-EPR experiments, the injected oocytes were previously frozen in liquid nitrogen.

In this study the MTSL nitroxide (2), routinely employed for SDSL-EPR studies, was not chosen as spin label because of the cleavage of the S-S bond between the protein and the label inside cells. In contrast to MTSL, maleimido-proxyl $\mathbf{1}$ was employed because the maleimide group reacts with cysteine residues by forming a C-S bond, expected to be more stable to reductive cleavage inside cells than the S-S one.

The reported work represents the proof-of-principle of in-cell EPR, since it demonstrated that EPR spectroscopy can potentially be used to follow protein conformational changes in the cellular environment and, at the same time, highlighted its forthcoming limits and challenges.<smiles>CN1C(C)(C)CC(N2C(=O)C=CC2=O)C1(C)C</smiles>

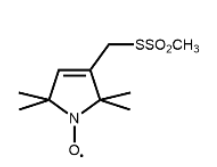

$\underline{\mathbf{2}}$

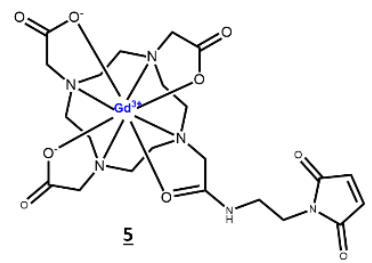

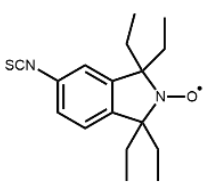

$\underline{3}$

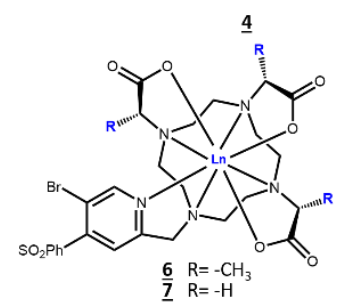

Figure 1. Spin Labels cited in this review: 3-maleimido-PROXYL (1), MTSL (2), 1,1,3,3-tetramethylisoindolin-5-isothiocyanate-2oxyl (으), M-TETPO (4) $), \mathrm{Gd}^{3+}$ DOTA-maleimide $(\underline{\mathbf{5}}), \mathrm{BrPSP}-\mathrm{DO}_{\mathrm{MAA}-G d 3^{+}} \underline{\mathbf{6}}$ and BrPSPy-DO3A-Gd ${ }^{3+} \underline{\mathbf{7}}$.

One limitation is related to the short lifetime of nitroxide labels in the cellular context. Their decay occurs because of the presence of antioxidants and enzymes in the cytoplasm that reduce the nitroxide group to the corresponding EPR silent hydroxylamine. Among the cellular reducing species, we can mention semi-quinone radicals, glutathione, species generated from the mitochondrial electron transport chain, $N A D(P) H-$ dependent enzymes, thioredoxin and other enzymes containing sulfhydryl groups. The nitroxide reduction thus limits the time window to acquire spectra of in-cell samples and, in the case of distance measurements, this leads to the loss of dipolar-coupled spin pairs. ${ }^{[27]}$

Another point concerns the bond between the spin label and the Cys residue on the choose system, as it has to be not reductively cleavable inside cells.

In addition, the restricted number of delivering methods of the labeled protein inside cells, that are currently available, represent another limitation of in-cell EPR.

In the following sections we will describe how the EPR community actively search for new methodologies and tools to tackle these limitations and make in-cell EPR spectroscopy a powerful and complementary tool for investigating biomolecule structure and dynamics while preserving its physiological environment.

\section{Spin labels for in-cell EPR studies}

Currently, among all the spin labels families, nitroxide radicals are the sole molecules able to combine the investigation of local protein structural dynamics in solution at physiological temperature ('solution-state' EPR) with the study of the 
biomolecule structure by inter-spin distance measurements (DEER).

Unfortunately, as already mentioned, a major hurdle is the short lifetime of nitroxide spin labels in the cellular context (see Figure 2). As reported in most of the in-cell EPR articles, nitroxide reduction can be limited by shock-freezing the sample in liquid nitrogen as soon as possible and to carry out EPR measurements on frozen solution. Even if quite successful, this approach limits in-cell studies to distance measurements with limited incubation period. To mitigate nitroxide reduction in cell, Saxena and coworkers mixed the nitroxide-labeled protein with a solution of an oxidizing agent such as $\mathrm{K}_{3} \mathrm{Fe}(\mathrm{CN})_{6}{ }^{[28]}$ The use of cell strains deficient of thioredoxin reductase and glutathione reductase (for example $E$. coli Origami®) was also suggested as a possible means to delay nitroxide reduction in cell. ${ }^{[29]}$

Besides these possibilities, the development of spin labels stable in the cellular environment has appeared as an important step to push in-cell EPR researches forward. In the last years, several studies dealing with the design and synthesis of spin labels stable in the cellular context have been carried out. Shielded-nitroxides, $\mathrm{Gd}^{3+}$ - and trityl-based spin labels have shown to be promising options.

In the following sections we provide a description of the principal families of spin labels currently employed for in-cell EPR studies. As already mentioned above, for SDSL-EPR studies in cell the spin label's reactive group responsible of the ligation of the target molecules needs to be stable to cleavage. In this manuscript, when possible, we will point up the reactive group properties of the depicted spin labels but we will not discuss them in depth. For an exhaustive discussion we suggest an interesting and detailed review recently appeared. ${ }^{30]}$

\subsection{Nitroxide-based spin labels}

Interest in nitroxide lifetime in biological context started more than 40 years ago. Several research groups investigated nitroxides EPR signal loss in different conditions in order to characterize the relationship between nitroxide structure and their reduction to hydroxylamine by ascorbate and other reductants. Generally, the reduction decay kinetics of nitroxides is obtained by following the low-field line of the nitroxide spectrum as function of time in the presence of a reducing agent.

The work of Keana et al. showed that the ring size of nitroxides has an impact on their reduction by ascorbate, i.e. pyrrolidine nitroxides (nitroxide ' $a$ ', 'b' and 'c' in Figure 2) being more resistant to reduction than piperidine (see nitroxide 'd', Figure 2) or doxylbased nitroxides ${ }^{[25 a]}$. Later, Rassat demonstrated that steric shielding of the nitroxide moiety changing the gem-dimethyl by gem-diethyl groups on isoindoline nitroxide efficiently slows down the reduction process. ${ }^{[31]}$ More recently, significant efforts have been made in the design and synthesis of nitroxides and nitroxidebased spin labels stable in the cellular context. Rajca and collaborators synthetized a series of sterically shielded pyrrolidine nitroxides and focused on their reduction properties in the presence of ascorbate and glutathione. ${ }^{[32]}$ Large excess of ascorbate is usually employed as a common reducing agent for such studies.

The comparison of reduction rates of the nitroxides under investigation by Rajca and collaborators, suggested that spirocyclohexyl nitroxides ${ }^{[33]}$ (nitroxide 'b' in Figure 2) are reduced slower than the corresponding gem-methyl nitroxides (nitroxide ' $c$ ' in Figure 2), while gem-ethyl nitroxides (nitroxide 'a' in Figure 2) are reduced at significantly slower rates, by a factor 20-70 compared to spirocyclohexyl nitroxides. Spirocyclohexyl groups thus confer some stability towards reduction but are less efficient in steric shielding compared to the ethyl groups. ${ }^{\text {[2a] }}$ The reduction properties of nitroxides bearing gem-tetracarboxylate groups, expected to be sterically bulkier than ethyl groups on the basis of DFT calculations, were also investigated. ${ }^{[34]}$ However, these nitroxides undergo very fast reduction in an ascorbate/glutathione solution mixture. The authors argue that, beside steric factors, other contributions governing nitroxide reduction, such as the polarity and the withdrawing/donating properties of substituents, have to be taken in account.

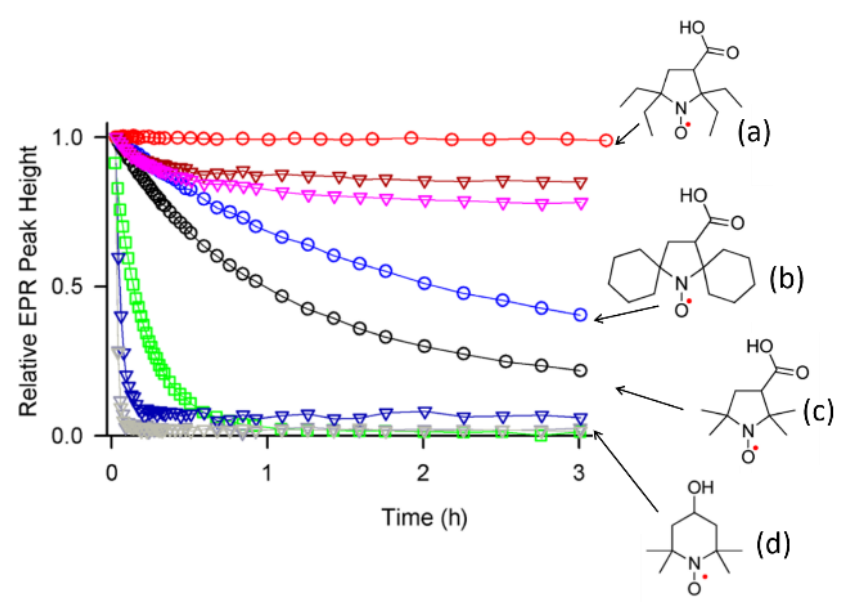

Figure 2. Example of a) gem-ethyl, b) spirocyclohexyl, c) gem-methyl and d) piperidine-based nitroxides and their reduction profiles $(0.2 \mathrm{mM})$ in $4 \mathrm{mM}$ ascorbate solution. The figure has been adapted with permission (J. T. Paletta et al. Org. Lett. 2012, 14 (20), 5322-5325). Copyright (2012) American Chemical Society. ${ }^{[32 a]}$

In parallel, Prisner and Sigurdsson and collaborators have studied and compared the effects of substituents on the free radical stability in four nitroxide families (specifically piperidine-, imidazolidine-, pyrrolidine-, and isoindoline-based nitroxides) in cytoplasmic extracts and in intact $X$. laevis oocytes. ${ }^{[35]}$ Besides confirming that bulky ethyl groups next to the nitroxide moiety represent the more effective stabilisation against reduction, this study highlighted that the reduction profiles obtained in cell extracts are slower than those obtained in cell and do not follow an exponential decay. ${ }^{[35]}$ The authors explain this result by admitting a competition between reducing (ascorbate, glutathione, NADH and NADPH) and oxidizing (metal enzymes, metal ion release, ROS and $\mathrm{O}_{2}$ ) processes present in the cell extract. Indeed, oxidizing agents, enzymes and Reactive Oxygen Species can re-oxidize the hydroxylamine back to nitroxide slowing down the reduction process. A similar trend has also been reported in other studies. ${ }^{\text {[28a, } 36]}$ Moreover, because of the drastic process of cell extract formation, the redox properties of the extracts are difficult to control and poorly reproducible. Cell extracts experiments are not equivalent to intact cell studies, but

\section{Author copy}


provide information that are difficult to obtain through in vitro experiment using one or a mixture of antioxidants.

Despite many studies have shed light on the design of nitroxides resistant to cellular reduction and the investigation of their redox properties in a physiological environment, only a few works concern the design and synthesis of new nitroxide spin labels (able to be grafted on a biomolecule). In the following sections, we describe three shielded nitroxide spin labels recently reported.

Spin label $\mathbf{3}$, an isoindoline-derived aromatic isothiocyanate, is able to react with amino groups. In the study reported by Saha et al. ${ }^{[37]}$, it is employed for the covalent grafting of nucleic acids via its specific reactivity towards 2' amino groups that can be inserted at the 2' position on the ribose moiety of uridine in RNA. Solution-state EPR studies of labeled oligonucleotides were necessary to investigate the ability of nitroxide $\underline{\mathbf{3}}$ in reporting on structural features. Interestingly, cw-EPR spectra of RNA duplexes were found to be broader than those obtained for the single labeled oligonucleotides, demonstrating that this nitroxide can be employed to follow conformational flexibility of nucleic acids.

Concerning the resistance to reduction, although the stability of spin label $\underline{\mathbf{3}}$ was demonstrated only in ascorbate solution and more investigations need to be conducted, the preliminary results presented clearly suggest that $\underline{\mathbf{3}}$ is a promising spin label for incell EPR studies. ${ }^{[37]}$

Spin label 4 (M-TETPO), exhibiting gem-diethyl groups and a maleimide moiety for protein conjugation via cysteine labeling, showed high resistance of the nitroxide moiety to reduction and of the linker to cleavage in ascorbate solutions, cell extracts and in oocytes. The property of M-TETPO in reporting on protein structural dynamics was investigated by labeling several regions of NarJ ( $25 \mathrm{kDa})$, a chaperone protein, and by comparing the solution state EPR spectra with those obtained by using the commercially available nitroxide $\underline{\mathbf{1}}$. These studies clearly demonstrated that M-TETPO nitroxide is a sensitive spin label for structural EPR studies of protein in solution and at physiological temperature. Following, the global structural changes occurring during the binding process between NarJ and its biological partner (NarGH), M-TETPO was proven to be a suitable spin label in distances measurements performed by DEER. ${ }^{[36 a]}$ After having established that the new nitroxide spin label is resistant to reduction and able to report on conformational changes on a model protein, M-TETPO has been used for the investigation of NarJ structural dynamics by performing $X$-band DEER experiments in intact $X$. laevis oocytes at endogenous concentration using $20 \mu \mathrm{M}$ of labeled protein ("bulk concentration").

During the review process for this review, an interesting article on nitroxide labels for in-cell EPR studies by Bleicken et al. appeared. In particular, they reported a gem-diethyl nitroxide spin label (IAG) able to target Cys residues by a iodo-acetamide group and, thus, leading to the generation of a C-S bond between the protein and the paramagnetic label.

Taken together, these results open up the perspective of achieving high resolution EPR studies of biomolecules in their native environment in solution as well as at cryogenic temperature.

\section{Author copy}

\subsection{Metal cations-based spin labels}

Spin labels based on paramagnetic metal centers represent an interesting alternative to nitroxide labels for in-cell EPR studies principally because they are insensitive to reduction.

In general, a metal-based spin label is composed by a ligand, able to coordinate a paramagnetic metal, and by a linking group, able to specifically react with a residue into the protein, more often Cys residues. Several paramagnetic metals $\left(\mathrm{Cu}^{2+}, \mathrm{Mn}^{2+}, \mathrm{Mo}^{5+}, \mathrm{Fe}^{3+}\right.$, $\mathrm{Gd}^{3+}$ for example) have already been successfully employed for distance measurements by DEER spectroscopy in vitro. ${ }^{[14 a, 21-22,}$ 22d, 38]

Concerning in-cell EPR applications, $\mathrm{Gd}^{3+}$ based spin labels are currently the most employed tags. Contrary to nitroxides, spin labels based on $\mathrm{Gd}^{3+}(\mathrm{S}=7 / 2)$ complexes are characterized by an enhanced sensitivity at high frequency and are free from orientation selection effects. Further details on inter-spin orientation selection studies can be found in several published works. ${ }^{[39]}$ In general, $\mathrm{Gd}^{3+}$ complexes are characterized by a broad frozen solution EPR spectrum except for the central transition line $(-1 / 2+1 / 2)$. As the width of the central transition line narrows by increasing the frequency, experiments involving $\mathrm{Gd}^{3+}$ tags are carried out at high frequency, with $95 \mathrm{GHz}$ being the most employed one. Several studies demonstrated that the EPR signal of $\mathrm{Gd}^{3+}$-tags is unaffected in the cellular environment. ${ }^{[6 \mathrm{c}, 40]}$ On the other hand, for in-cell applications, $\mathrm{Gd}^{3+}$-tags must have a very high affinity for the coordinated metal to avoid the presence of free $\mathrm{Gd}^{3+}$ ions in the cellular suspension that leads to an increase of the background signal and a decrease of the modulation depth in DEER experiments.

Concerning in-cell EPR experiments, an elegant study showed DEER measurements successfully carried out on the ubiquitin protein $(8.5 \mathrm{kDa})$ doubly labeled with $\mathrm{Gd}^{3+}$-DOTAmaleimide tag ( $\underline{\mathbf{5}}$, Figure 1$)$ after its delivery in eukaryotic cells (HeLa) by hypotonic swelling. These experiments were conducted at $10 \mathrm{~K}$, at $95 \mathrm{GHz}$ (W-band) and at a bulk concentration of $\sim 5 \mu \mathrm{M} \cdot{ }^{[40 \mathrm{~b}]}$ Since the distance distributions obtained in cell were substantially the same as those obtained in vitro, the authors hypothesized that the overall structure of ubiquitin does not change inside cells. This could also be explained considering that ubiquitin is a globular, well-structured protein, for which the impact of the cellular environment could be negligible. Nevertheless, the background decay of the DEER trace observed in cell was stronger than that observed in vitro. This is a direct consequence of the crowding in the cells which leads to higher local concentrations of the delivered protein, namely inhomogeneous distribution within the cell.

Currently, several research groups are highly active in the design of new $\mathrm{Gd}^{3+}$-based spin labels with optimized properties, such as i) a linker stable in the cellular environment; ii) a very high affinity for the coordinated metal to avoid the presence of $\mathrm{Gd}^{3+}$ ions free in the cellular suspension; iii) a short and rigid linker to decrease the width of distance distribution; ${ }^{[41]} \mathrm{iv}$ ) a small ZFS (Zero Field Splitting) parameter in order to have the narrower central transition and thus the best signal amplitude ${ }^{[42]}$ and $v$ ) a smaller tag size. ${ }^{[41,43]}$ For example, a newly designed $\mathrm{Gd}^{3+}$-based tag (4-vinyl-PyMTA) was demonstrated to be a valuable spin label to selectively target Cys residues of a proline rich peptide thanks to a vinyl group. In particular, the grafting reaction is a Michael 
addition of the thiol group of Cys to the vinyl group of the spin label, which results in a S-C bond between the label and the protein, a bond expected to be more resistant than S-S towards cleavage in cellular environment.

The stability of 4-vinyl-PyMTA in cellular conditions was evaluated in cell extracts and after micro-injection in $X$. laevis oocytes. ${ }^{[40 a]}$ More recently, Goldfarb and collaborators reported on two spin labels, BrPSPy- DO3MA-Gd3 $3^{+} \underline{\mathbf{6}}$ and BrPSPy-DO3A-Gd ${ }^{3+} \underline{7}^{[44]}$ Concerning these two spin labels, the large $\mathrm{Gd}^{3+}$ binding constant of DOTA-like group gives them high stability, the coordination of the $\mathrm{Gd}^{3+}$ by a pyridine nitrogen gives higher rigidity than the DOTA-like one and the 3-bromo-phenylsulfonylpyridine moiety allows selective grafting of Cys residues of ubiquitin variants in mild conditions $(\mathrm{pH} 8)$ in a rather short time (6 hours of reaction) with $80 \%$ of labeling yield. ${ }^{[44 a]}$ Note that, in the case of spin label $\underline{\mathbf{7}}$, also immunoglobulin G-binding protein (GB1) was successfully labeled. ${ }^{[44 b]}$ After the delivery of the labeled protein by hypotonic swelling and electroporation into HeLa cells, spin labels $\underline{\mathbf{6}}$ and $\underline{\mathbf{z}}$ were successfully employed to perform in-cell DEER measurements at W-band under cryogenic temperature. ${ }^{[44 a]}$ In particular, in the case of protein labeled with $\underline{\mathbf{Z}}$, the sensitivity of in-cell DEER was higher than in the case of labeling with $\underline{\mathbf{6}}$. This being related to a higher phase memory time and a smaller ZFS of spin label $\underline{\mathbf{7}}$, which differs from $\underline{\mathbf{6}}$ in the absence of a methyl group from the acetate arms.

\subsection{Trityl-based spin labels}

Triarylmethyl radicals (trityl or TAM) are carbon-centered radicals combining a high stability in the cellular environment and a narrow EPR line with relaxation properties allowing distance measurements at physiological temperatures. For these reasons they appeared as promising candidates for in-cell EPR experiments.

Trityl chemical structure is characterized by six thioacetonide moieties, important for the stability of the radical, and by para-position substituents important to modulate their solubility.

Examples of in vitro SDSL-EPR involving trityl spin labels were already reported for proteins, ${ }^{[17,}{ }^{45]}$ polymers ${ }^{[46]}$ and oligonucleotides $^{[47]}$.

Figure 3. Trityl-based spin labels.

However, reduction processes of trityl exist in vivo. While trityl radicals' stability has already been well characterized in human blood, ${ }^{[48]}$ few studies report on the investigations of their stability inside cells. ${ }^{[35,49]}$ In a recent study, a trityl radical linked to a poly-arginine chain, that could cross the membrane of human cells (MDA-MB-231) was prepared and its EPR signal was found to be stable at least for two hours. ${ }^{[49]}$ As the reduction properties depend on the chemical structure, further improvement of trityl structure could tune their bio-reduction properties.<smiles>[R]C(=O)c1c2c(c(C(c3c4c(c(C(=O)O)c5c3SC(C)(C)S5)SC(C)(C)S4)c3c4c(c(C(=O)O)c5c3SC(C)(C)S5)SC(C)(C)S4)c3c1SC(C)(C)S3)SC(C)(C)S2</smiles><smiles>[R5]CCC#CCC#[R5]</smiles>

A recent work reported in details on the synthesis of new trityl-based tags ( $\underline{\mathbf{8}}$, Figure 3 ) and their investigation as spin labels for in vitro and in-cell EPR studies. ${ }^{[50]}$

Spin label $\underline{\mathbf{z}}\left(R_{1}, R_{2}\right.$ and $\left.R_{3}\right)$ showed to be soluble and stable in aqueous solutions, at room temperature and in the presence of molecular oxygen during at least 3 hours. Its ability to react with cysteine residues was investigated by labeling a cytochrome P450 protein, called CYP101. The stability towards cleavage in a cellular context of the thioether bond and of the triazole linkage makes SL7- $\mathrm{R}_{2}$ and $\mathrm{SL7}-\mathrm{R}_{3}$ suitable for in-cell EPR studies, respectively. Indeed, distance measurements involving an intrinsic paramagnetic cofactor (an iron (III)), present in the CYP101 protein, and the trityl spin label were performed in cell. To this purpose, about twenty $X$. laevis oocytes were microinjected with a solution of the labeled CYP101 protein. After injection, the oocytes were inserted in a capillary and shockfrozen. The final in-cell concentration (bulk) was $\sim 250 \mu \mathrm{M}$.

The time traces obtained by measuring trityl-Fe $\mathrm{F}^{\text {III }}$ distances by RIDME at Q-band and at $25 \mathrm{~K}$ in cell show a SNR 10 times less than obtained for in vitro distance measurements. The authors explain this result by considering that they have a difficulty in controlling the iron content of the protein, that seems to be lower than the expected one. Moreover, the presence of intrinsic cellular $\mathrm{Mn}^{2+}$ could enhance the relaxation of the $\mathrm{Fe}^{3+}$. However, even with this low SNR, the distance distribution obtained in cell was found to be very similar to the one obtained in vitro.

Despite the size of trityl-based spin labels, which could perturb the structure of the protein under investigation, the results achieved in this work are an interesting demonstration of the feasibility of in-cell distances measurements.

As mentioned before, the possibility to perform distance measurements at physiological condition (in solution and at room temperature) is very attractive, especially when studying biological systems. However, to this aim further improvements in the design of trityl-based spin labels are necessary, for example in modulating spin label properties which are key factor for the increase of $T_{m} \cdot{ }^{[51]}$

\section{Author copy}



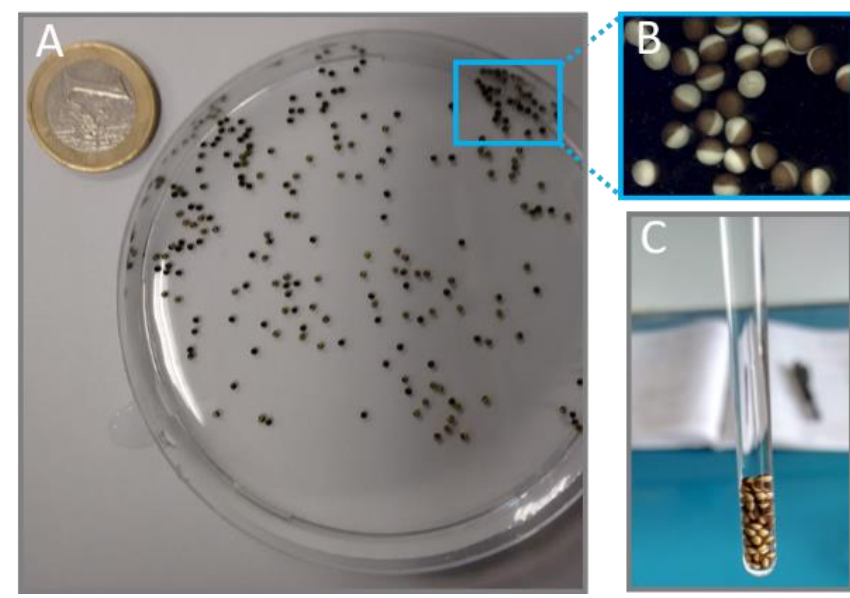

Figure 4. A) and B) Xenopus laevis oocytes at stage VI. C) An X-band EPR tube filled with $\sim 40 \mathrm{X}$. laevis oocytes.

\section{Cellular systems and protein delivery}

In order to perform in-cell EPR experiments, biological macromolecules are generally labeled with the appropriate spin label prior to its delivery inside cells.

$X$. laevis oocytes (Figure 4) have been widely used cells [40a, ${ }^{52]}$ owing to the fact that they can be easily micro-injected, that they are large cells $(\sim 1 \mu \mathrm{L}$ in volume) and that the amount of introduced protein can be controlled. Oocytes can be studied at $X$ or $Q$ band. At X-band between 50 and 100 oocytes are necessary, while at $Q$-band few oocytes (5) are enough. ${ }^{[53]}$

Despite the fact that they are useful model cells, at least two drawbacks can be related to the use of oocytes as host cells for in-cell experiments. First, they require highly concentrated labeled protein solutions before injection, to avoid excessive dilution in the oocyte cytoplasm. Secondly, by taking into account that prokaryotic and eukaryotic cells show important dissimilarities in terms of compartmentation and viscosity and that these differences could have a repercussion on the structural properties of the studied system, oocytes could not be the appropriate cellular environment to study functional interactions between bacterial proteins, for example. Effectively, while eukaryotic cells contain organelles (as the endoplasmic reticulum, Golgi body and mitochondria for example), have a defined nucleus and an organized cytoskeleton, bacterial cells do not contain a well-defined nucleus, thus DNA molecules are in an open region in the cytosol (the nucleoid), they do not contain any membrane-bound organelle and they present elements of a cytoskeletal structure. Moreover, bacterial cells are smaller $(0.5-3 \mu \mathrm{M})$ than eukaryotic ones $(2-100 \mu \mathrm{M})$.

A research line in in-cell EPR and NMR studies is related to the improvement of protein delivery methods inside cells with the aim to reach as much as possible the physiological concentration.

Permeabilisation of the membrane by hypotonic swelling ${ }^{[40 b]}$ and electroporation ${ }^{[44 a, 54]}$ are two approaches that have been successfully used in the field of in-cell EPR to deliver exogenous proteins in eukaryotic cells. An osmotic gradient between the intracellular and the extracellular compartment (hypotonic swelling) or a high-voltage electric pulse applied to a cell suspension (electroporation), allow the temporary destabilization of the cellular membrane. The result is that the membrane permeability increased and, thanks to a concentration gradient, the labeled protein can then cross the membrane and entry the cell. Not internalized proteins are then removed by a washing procedure. To confirm the delivery occurred, in general, the internalization is also monitored by microscopy using a fluorescently labeled protein.

Hypotonic swelling and electroporation are particularly suited to treat a large number of cells at the same time and in a relatively short time. Moreover, no chemical conjugation is required.

However, these delivery approaches can affect in an irreversible way the cellular membrane and consequently affect cell viability, cell morphology and proliferation rate. ${ }^{[55]}$ In the case of electroporation, the percentage of viable cells is in general lower than for cells treated by hypotonic swelling, while the amount of apoptotic cells and the production of ROS was found to be higher.

A milder approach in term of cell viability is that based on the direct biosynthesis of the spin-labeled protein in vivo. This elegant method, based on the genetic encoding of nitroxide amino acids in response to the amber stop codon (TAG) by a tRNAPyl/pyrrolysyl-tRNA-synthetase pairs in $E$. coli, enables the incorporation of the nitroxide-modified amino acid at defined sites of the protein with a minimal perturbation of the natural environment of the protein. ${ }^{[56]}$ This approach imposes the design and the synthesis of amino acids carrying the nitroxide moiety.
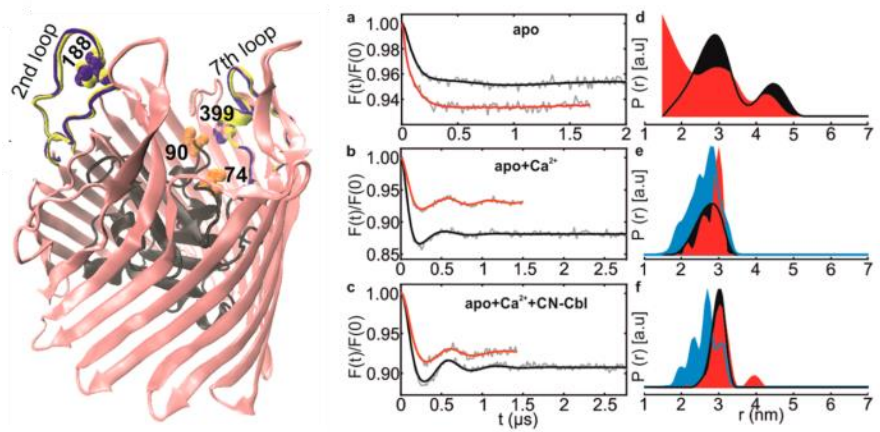

Recently, a highly efficient incorporation of lysine carrying a nitroxide side-chain (SLK-1, Figure 5) into E. coli thioredoxin has been reported. ${ }^{[56 a]}$ The authors demonstrated an high degree of incorporation of spin labeled Lys (99\%) into several variants of the protein (mono and double SLK-1 variants). Moreover, they were able to demonstrate the detection of an EPR signal in E. coli cells at room temperature owing to the labeled protein. The EPR signal of the free spin labeled amino acid present in the cytoplasm was minor and showed a different spectral shape than that of the in vivo spin-labeled thioredoxin. This result also confirms that the spin labeled protein reaches sufficient expression levels to be detected by EPR. Despite these encouraging results, inter-spin distance measurements were not possible because of the spinspin interaction loss, related to nitroxide signal decay. This can be principally due to intracellular reduction of the nitroxide and to a possible degradation of the protein by enzymes (proteases). ${ }^{[57]}$ An additional point needing improvement concerns the spin label flexibility. The high distance of the spin labeled moiety from the 
protein backbone and its flexibility results in a very sharp room temperature $\mathrm{CW}$ spectrum and provides limited dynamic information associated to broad distance distributions in DEER experiments.
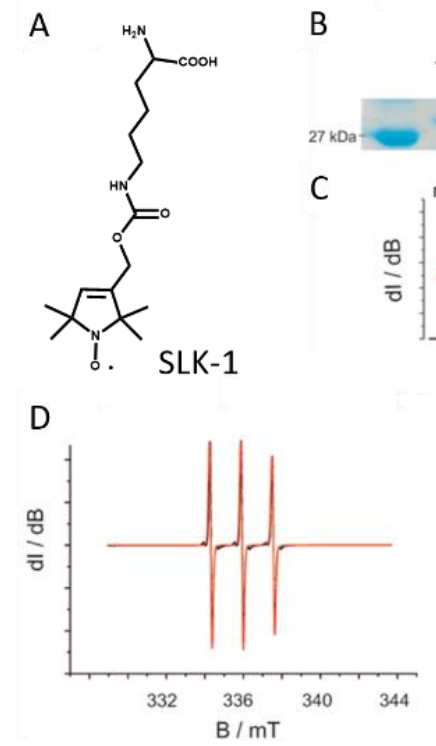

B

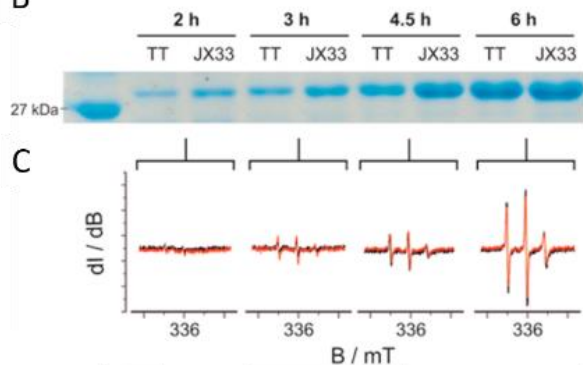

$\mathrm{E}$

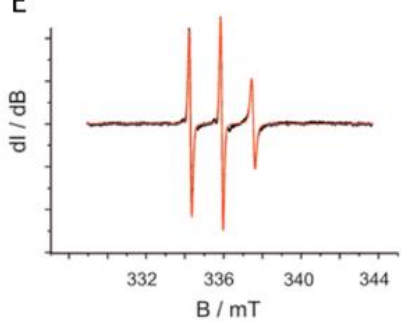

Figure 5. A) Nitroxide-based unnatural amino acid SLK-1. B) Expression kinetics of SLK-1-labeled protein in E. coli strains Top10 (TT) and JX33 analyzed by SDS-PAGE. C) EPR spectra of SLK-1-labeled protein samples from panel B (Top10 and JX33 shown in red and black, respectively). D) X-band EPR spectrum of SLK-1 in buffer. E) X-band EPR spectrum of purified thioredoxin labeled with SLK-1 in buffer. Experimental and simulated spectra are shown in red and black, respectively. Adapted with permission (M. J. Schmidt et al. J. Am. Chem. Soc. 2014, 136, 4, 1238-1241). ${ }^{[66 a]}$ Copyright (2014) American Chemical Society.

Another work, based on in vivo bio-synthesis of the labeled protein and self-assembled metal spin labels (SAMSL) was recently showed. ${ }^{\left[{ }^{[5]}\right.}$ A genetically encodable metal ion-binding tag was introduced at each of the terminus of a model protein, a 3helix-bundle. In this case the binding tag, a peptide sequence (YIDTNNDGWIEGDEL) capable of specifically bind lanthanides $\left(\mathrm{Gd}^{3+}\right)$, was genetically encoded and incorporated in vivo. The 3helix-bundle was overexpressed in $E$. coli cells, grown on a medium supplemented with $\mathrm{Gd}^{3+}(500 \mu \mathrm{M})$. At least $4 \mathrm{~h}$ of growth on $\mathrm{Gd}^{3+}$ medium were necessary to reach a good level of $\mathrm{Gd}^{3+}$ uptake. Despite the low binding constant of $\mathrm{Gd}^{3+}$ and the excess of free $\mathrm{Gd}^{3+}$ limiting the signal-to-noise ratio, the authors were able to detect dipolar modulation signal for the " $\mathrm{Gd}^{3+}$ : 3-helix-bundle $\mathrm{Gd}^{3+"}$ and the distance distribution obtained in cell was very similar to that obtained in vitro.

Figure 6. On the left, apo-BtuB structure (PDB 1NQE). On the right: a-c, background corrected Q-band DEER traces for the double mutant in E. colicells (red) and in isolated outer membrane (black) in the absence and in the presence of ligands; d-f, distance distributions and their simulations. Adapted with permission (B. Joseph et al. J. Am. Chem. Soc. 2016, 138, 6, 1844-1847). ${ }^{[48 b]}$ Copyright (2016) American Chemical Society.

\section{Author copy}

Without a doubt, the approaches presented in this paragraph are very interesting and appear as powerful tools for in-cell EPR studies.

\section{Membrane proteins in whole cells}

Among in-cell EPR studies, a big challenge is the investigation of membrane protein structure in the native lipid environment.

An excellent example concerns the investigation of the structural dynamics of the outer membrane cobalamin transporter BtuB, a $\beta$-barrel protein. ${ }^{[59]}$ Notably, it was possible to detect structural changes induced by ligand binding in intact $E$. coli cells. All the BtuB variants used in this work carry cysteine residues in extracellular loops of the membrane protein. The cysteine variants were overexpressed in E. coli and the whole cell suspension was then labeled with MTSL (2 , Figure 1), an already established procedure. ${ }^{[60]}$

Thanks to several control experiments and assuming that outer membrane proteins in $E$. coli are in general free from Cys residues, the authors were able to demonstrate that the EPR signal observed after labeling of the whole cell suspension is specific of the BtuB protein. In fact, the free MTSL label which could reach the periplasm or, eventually, the cytoplasm and thus react with Cys of other proteins is rapidly reduced to an EPR silent specie, in a similar way for what already observed for nitroxide labels. ${ }^{[35-36,52 c]}$ In this case the reduction of nitroxide is desired to eliminate the unwanted signals.

A double BtuB mutant, bearing 2 Cys residues (188 and 399, Figure 6) in two extra cellular loops (the second and the seventh loop) was overexpressed in the cells and successfully labeled with MTSL. The spin concentration reached with the labeling of BtuB in the cellular suspension was of $30 \mu \mathrm{M}$, and this concentration allowed good quality DEER measurements in intact $E$. coli cells. The core of this work, however, is the detection of changes in distance distribution after the addition of $\mathrm{BtuB}$ ligands $\left(\mathrm{Ca}^{2+}\right.$ ions and cyanocobalamin) to the cell suspension. These changes were explained taking into account conformational changes of 
one of the investigated extracellular loop (second loop) and are also supported by X-ray crystallography data. This is the first evidence of structural changes captured in the native cellular environment.

Another example of membrane protein studied by SDSL-EPR in native conditions concerns $E$. coli colicin A (ColA), a poreforming toxin produced by $E$. coli. Steinhoff and collaborators characterized ColA oligomerisation upon insertion in $E$. coli membrane by both room temperature $\mathrm{cW}$-EPR and DEEREPR. ${ }^{[29]}$ To this purpose, ColA was previously spin labeled in vitro and then incubated with liposomes prepared from $E$. coli polar lipids (artificial membrane) and with Origam ${ }^{\circledR}$ E.coli cells.

The solution-state EPR spectra of labeled ColA in artificial or native membranes showed very similar lineshapes, suggesting that the nitroxide mobility is very similar in the two conditions. Thus, the authors conclude admitting that ColA should bind to artificial and to native membranes in a very similar way. Concerning DEER experiments, even if the signal-to-noise ratio was poor, a dipolar interaction was detected in intact cells, and most important, at the native concentration of the membrane protein.

\section{Conclusion}

All the studies presented in this review show that SDSLEPR can be successfully applied to investigate biological macromolecules in cellular conditions. However, a lot of work still need to be done and both methodological and technical developments are required.

For example, while distance measurements in-cell are quite established, the structural dynamics study of a protein or a nucleic acid in-cell in physiological conditions by solution-state EPR is still very challenging.

In the near future, efforts will be partly directed toward the design of spin labels and paramagnetic non-natural amino acids with improved chemical properties (for example concerning their stability in the cellular environment) and characterized by enhanced spectroscopic features that will have a high impact on the biomacromolecule study directly inside cells.

Particular effort should be directed in order to make possible the investigation of protein-protein or protein-ligand interaction. In particular, this will be possible by improving tools to engineer proteins in living cells based on genetic code expansion and unnatural amino acid mutagenesis and on a better control of the expression of two or more proteins with the use of inducible promoters.

Obviously, questions concerning the cellular viability, protein compartmentation and localization should be addressed in-depth in the future.

Understanding how the natural cellular environment affects protein structure, dynamics and consequently protein function, and unravelling protein-protein interactions in physiologically relevant conditions represent an extraordinary step forward in the field of cellular structural biology and will provide fundamental elements to understand how cells work.

\section{Acknowledgements}

We thank A. Magalon and D. Normanno for helpful discussion. We are grateful to $E$. Etienne and G. Gerbaud from the national TGE RPE facilities (IR 3443). We acknowledge financial support from the Agence Nationale de la Recherche (contract ANR15CE29-0022-02 and ANR-18-CE11-0007-01) and from the Conseil Régional of Région Sud (APEX-2015).

Keywords: EPR • in-cell spectroscopy • spin labels • SDSL • structural biology

[1] L. M. Charlton, G. J. Pielak, Proceedings of the National Academy of Sciences 2006, 103, 11817-11818.

[2] F.-X. Theillet, A. Binolfi, T. Frembgen-Kesner, K. Hingorani, M. Sarkar, C. Kyne, C. Li, P. B. Crowley, L. Gierasch, G. J. Pielak, A. H. Elcock, A. Gershenson, P. Selenko, Chemical Reviews 2014, 114, 6661-6714.

[3] aS. Schopper, A. Kahraman, P. Leuenberger, Y. Feng, I. Piazza, O. Müller, P. J. Boersema, P. Picotti, Nature protocols 2017, 12 , 2391; bJ. Gan, G. Ben-Nissan, G. Arkind, M. Tarnavsky, D. Trudeau, L. Noda Garcia, D. S. Tawfik, M. Sharon, Anal. Chem. 2017, $89,4398-4404$.

[4] aM. Schneider, A. Belsom, J. Rappsilber, Trends Biochem. Sci 2018, 43, 157-169; bR. M. Kaake, X. Wang, A. Burke, C. Yu, W. Kandur, Y. Yang, E. J. Novtisky, T. Second, J. Duan, A. Kao, S. Guan, D. Vellucci, S. D. Rychnovsky, L. Huang, Molecular \& cellular proteomics : MCP 2014, 13, 3533-3543.

[5] aG. Bertolin, F. Sizaire, G. Herbomel, D. Reboutier, C. Prigent, M. Tramier, Nature Communications 2016, 7, 12674; bI. Konig, A. Zarrine-Afsar, M. Aznauryan, A. Soranno, B. Wunderlich, F. Dingfelder, J. C. Stuber, A. Pluckthun, D. Nettels, B. Schuler, Nature methods 2015, 12, 773-779.

[6] aM. Kaplan, A. Cukkemane, G. C. P. van Zundert, S. Narasimhan, M. Daniëls, D. Mance, G. Waksman, A. M. J. J. Bonvin, R. Fronzes, G. E. Folkers, M. Baldus, Nature methods 2015, 12, 649; bE. Luchinat, L. Banci, Acc. Chem. Res. 2018, 51, 1550-1557; cF. X. Theillet, A. Binolfi, B. Bekei, A. Martorana, H. M. Rose, M. Stuiver, S. Verzini, D. Lorenz, M. van Rossum, D. Goldfarb, P. Selenko, Nature 2016, 530, 45-50; dR. Hänsel, L. M. Luh, I. Corbeski, L. Trantirek, V. Dötsch, Angew. Chem. Int. Ed. 2014, 53, 10300-10314; eC. Kyne, P. B. Crowley, The FEBS journal 2016, 283, 3016-3028; fL. Barbieri, E. Luchinat, L. Banci, Nature protocols 2016, 11, 1101-1111.

[7] aS. Dzatko, M. Krafcikova, R. Hänsel-Hertsch, T. Fessl, R. Fiala, T. Loja, D. Krafcik, J.-L. Mergny, S. FoldynovaTrantirkova, L. Trantirek, Angew. Chem. Int. Ed. 2018, 57, 2165-2169; bR. Hänsel, F. Löhr, S. Foldynová-Trantírková, E. Bamberg, L. Trantírek, V. Dötsch, Nucleic Acids Research 2011, 39, 5768-5775.

[8] aG. Jeschke, Emerging Topics in Life Sciences 2018; bS. S. A., S. S. Th., Eur. J. Org. Chem. 2012, 2012, 2291-2301; cM. M. Haugland, J. E. Lovett, E. A. Anderson, Chem Soc Rev 2018, 47, 668-680; dP. Roser, M. J. Schmidt, M. Drescher, D. Summerer, Organic \& Biomolecular Chemistry 2016, 14, 5468 5476; eE. Bordignon, in eMagRes, (eds R. K. Harris and R. L. Wasylishen). ed., 2017; fO. Schiemann, T. F. Prisner, Quarterly reviews of biophysics 2007, 40, 1-53; gN. Le Breton, M. Martinho, E. Mileo, E. Etienne, G. Gerbaud, B. Guigliarelli, V. Belle, Frontiers in molecular biosciences 2015, 2, 21.

[9] in eMagRes.
[10] W. L. Hubbell, H. S. McHaourab, C. Altenbach, M. A. Lietzow, W. L. Hubbell, H. S. McHaourab, C. Altenbach, M. A.
Structure (London, England : 1993) 1996, 4, 779-783. aC. Gmeiner, D. Klose, E. Mileo, V. Belle, S. R. A. Marque, G. Dorn, F. H. T. Allain, B. Guigliarelli, G. Jeschke, M. Yulikov, J Phys Chem Lett 2017, 4852-4857; bM. Lorenzi, C. Puppo, R. 
Lebrun, S. Lignon, V. Roubaud, M. Martinho, E. Mileo, P. Tordo, S. R. Marque, B. Gontero, B. Guigliarelli, V. Belle, Angew Chem Int Ed Engl 2011, 50, 9108-9111; cE. Mileo, E. Etienne, M. Martinho, R. Lebrun, V. Roubaud, P. Tordo, B. Gontero, B. Guigliarelli, S. R. Marque, V. Belle, Bioconjugate chemistry 2013, 24, 1110-1117.

[12] M. Palombo, A. Bonucci, E. Etienne, S. Ciurli, V. N. Uversky, B. Guigliarelli, V. Belle, E. Mileo, B. Zambelli, Scientific reports 2017, 7, 5977 .

[13] B. Verhalen, R. Dastvan, S. Thangapandian, Y. Peskova, H. A Koteiche, R. K. Nakamoto, E. Tajkhorshid, H. S. McHaourab, Nature 2017, 543, 738-741.

[14] aE. H. Abdelkader, M. D. Lee, A. Feintuch, M. R. Cohen, J. D Swarbrick, G. Otting, B. Graham, D. Goldfarb, J Phys Chem Lett 2015, 6, 5016-5021; bK. Halbmair, J. Seikowski, I. Tkach, C. Hobartner, D. Sezer, M. Bennati, Chemical Science 2016, 7, 3172-3180; cM. Pannier, S. Veit, A. Godt, G. Jeschke, H. W. Spiess, Journal of Magnetic Resonance 2000, 142, 331-340.

[15] T. Schmidt, M. A. Walti, J. L. Baber, E. J. Hustedt, G. M. Clore, Angew Chem Int Ed Engl 2016, 55, 15905-15909.

[16] S. Milikisyants, F. Scarpelli, M. G. Finiguerra, M. Ubbink, M. Huber, Journal of magnetic resonance (San Diego, Calif. : 1997) 2009, 201, 48-56.

[17] Z. Yang, Y. Liu, P. Borbat, J. L. Zweier, J. H. Freed, W. L. Hubbell, Journal of the American Chemical Society 2012, 134 9950-9952.

[18] P. Schops, P. E. Spindler, A. Marko, T. F. Prisner, Journal of magnetic resonance (San Diego, Calif. : 1997) 2015, 250, 5562.

[19] aM. M. Haugland, A. H. El-Sagheer, R. J. Porter, J. Peña, T. Brown, E. A. Anderson, J. E. Lovett, Journal of the American Chemical Society 2016, 138, 9069-9072; bO. Schiemann, N. Piton, Y. Mu, G. Stock, J. W. Engels, T. F. Prisner, Journal of the American Chemical Society 2004, 126, 5722-5729; cN. Piton, Y. Mu, G. Stock, T. F. Prisner, O. Schiemann, J. W. Engels, Nucleic Acids Research 2007, 35, 3128-3143; dP. Z. Qin, I. S. Haworth, Q. Cai, A. K. Kusnetzow, G. P. G. Grant, E. A. Price, G. Z. Sowa, A. Popova, B. Herreros, H. He, Nature protocols 2007, 2, 2354; eL. S. Stelzl, N. Erlenbach, M. Heinz, T. F. Prisner, G. Hummer, Journal of the American Chemical Society 2017, 139, 11674-11677; fA. Marko, V. Denysenkov, D. Margraf, P. Cekan, O. Schiemann, S. T. Sigurdsson, T. F. Prisner, J Am Chem Soc 2011, 133, 13375-13379.

[20] aN. R. Kamble, S. T. Sigurdsson, Chemistry (Weinheim an der Bergstrasse, Germany) 2018, 24, 4157-4164; bS. Saha, T. Hetzke, T. F. Prisner, S. T. Sigurdsson, Chem. Commun. 2018 , 54, 11749-11752

[21] aA. Collauto, A. Feintuch, M. Qi, A. Godt, T. Meade, D. Goldfarb, Journal of Magnetic Resonance 2016, 263, 156-163; bA. Potapov, H. Yagi, T. Huber, S. Jergic, N. E. Dixon, G. Otting, D. Goldfarb, Journal of the American Chemical Society 2010, 132, 9040-9048.

[22] aA. V. Astashkin, A. Rajapakshe, M. J. Cornelison, K. JohnsonWinters, J. H. Enemark, The Journal of Physical Chemistry B 2012, 116, 1942-1950; bT. F. Cunningham, M. R. Putterman, A Desai, W. S. Horne, S. Saxena, Angew. Chem. Int. Ed. 2015, 54 6330-6334; cS. Ruthstein, M. Ji, P. Mehta, L. Jen-Jacobson, S. Saxena, The journal of physical chemistry. B 2013, 117, 62276230; dD. Banerjee, H. Yagi, T. Huber, G. Otting, D. Goldfarb, The Journal of Physical Chemistry Letters 2012, 3, 157-160; eA. Martorana, Y. Yang, Y. Zhao, Q.-F. Li, X.-C. Su, D. Goldfarb, Dalton Trans. 2015, 44, 20812-20816; fH. Y. V. Ching, F. C. Mascali, H. C. Bertrand, E. M. Bruch, P. DemayDrouhard, R. M. Rasia, C. Policar, L. C. Tabares, S. Un, The Journal of Physical Chemistry Letters 2016, 7, 1072-1076; gM. Ji, S. Ruthstein, S. Saxena, Acc. Chem. Res. 2014, 47, 688-695. aM. Ezhevskaya, E. Bordignon, Y. Polyhach, L. Moens, S Dewilde, G. Jeschke, S. Van Doorslaer, Mol. Phys. 2013, 111, 2855-2864; bM. Yulikov, in Electron Paramagnetic Resonance: Volume 24, Vol. 24, The Royal Society of Chemistry, 2015, pp. 1-31; cGregory E. Merz, Peter P. Borbat, Ashley J. Pratt, Elizabeth D. Getzoff, Jack H. Freed, Brian R. Crane, Biophys. J.
2014, 107, 1669-1674; dN. Le Breton, M. Martinho, K. Kabytaev, J. Topin, E. Mileo, D. Blocquel, J. Habchi, S. Longhi, A. Rockenbauer, J. Golebiowski, B. Guigliarelli, S. R. Marque, V. Belle, Physical chemistry chemical physics : PCCP 2014, 16 , 4202-4209.

[24] B. Commoner, J. J. Heise, J. Townsend, Proceedings of the National Academy of Sciences of the United States of America 1956, 42, 710-718.

[25] aJ. F. Keana, S. Pou, G. M. Rosen, Magnetic resonance in medicine 1987, 5, 525-536; bH. M. Swartz, M. Sentjurc, P. D. Morse, 2nd, Biochim Biophys Acta 1986, 888, 82-90; cR. M. Davis, S. Matsumoto, M. Bernardo, A. Sowers, K. Matsumoto, M. C. Krishna, J. B. Mitchell, Free radical biology \& medicine 2011, 50, 459-468.

[26] R. Igarashi, T. Sakai, H. Hara, T. Tenno, T. Tanaka, H. Tochio, M. Shirakawa, J Am Chem Soc 2010, 132, 8228-8229.

[27] M. Azarkh, O. Okle, P. Eyring, D. R. Dietrich, M. Drescher, Journal of magnetic resonance (San Diego, Calif. : 1997) 2011, $212,450-454$

[28] aM. J. Lawless, A. Shimshi, T. F. Cunningham, M. N. Kinde, P. Tang, S. Saxena, Chemphyschem : a European journal of chemical physics and physical chemistry 2017, 18, 1653-1660; bK. Singewald, M. J. Lawless, S. Saxena, Journal of Magnetic Resonance 2019, 299, 21-27.

[29] S. Dunkel, L. P. Pulagam, H. J. Steinhoff, J. P. Klare, Physical chemistry chemical physics : PCCP 2015, 17, 4875-4878.

[30] M. M. Haugland, J. E. Lovett, E. A. Anderson, Chem. Soc. Rev. 2018, 47, 668-680.

[31] L. Marx, A. Rassat, Chemical communications (Cambridge England) 2002, 632-633.

[32] aJ. T. Paletta, M. Pink, B. Foley, S. Rajca, A. Rajca, Organic letters 2012, 14, 5322-5325; bY. Wang, J. T. Paletta, K. Berg, E. Reinhart, S. Rajca, A. Rajca, Org. Lett. 2014, 16, 5298-5300. aV. Meyer, M. A. Swanson, L. J. Clouston, P. J. Boratynski, R. A. Stein, H. S. McHaourab, A. Rajca, S. S. Eaton, G. R. Eaton, Biophysical journal 2015, 108, 1213-1219; bA. Rajca, V. Kathirvelu, S. K. Roy, M. Pink, S. Rajca, S. Sarkar, S. S. Eaton, G. R. Eaton, Chemistry - A European Journal 2010, 16, 57785782.

[34] S. Huang, H. Zhang, J. T. Paletta, S. Rajca, A. Rajca, Free Radical Res. 2018, 52, 327-334.

[35] A. P. Jagtap, I. Krstic, N. C. Kunjir, R. Hansel, T. F. Prisner, S. T. Sigurdsson, Free radical research 2015, 49, 78-85 aG. Karthikeyan, A. Bonucci, G. Casano, G. Gerbaud, S. Abel, V. Thomé, L. Kodjabachian, A. Magalon, B. Guigliarelli, V. Belle, O. Ouari, E. Mileo, Angew. Chem. Int. Ed. 2018, 57, 1366-1370; bK. Chen, H. M. Swartz, Biochimica et Biophysica Acta (BBA) - Molecular Cell Research 1988, 970, 270-277.

[37] S. Saha, A. P. Jagtap, S. T. Sigurdsson, Chem. Commun. 2015 $51,13142-13145$

[38] aT. F. Cunningham, M. D. Shannon, M. R. Putterman, R. J. Arachchige, I. Sengupta, M. Gao, C. P. Jaroniec, S. Saxena, The Journal of Physical Chemistry B 2015, 119, 2839-2843; bC. Gmeiner, D. Klose, E. Mileo, V. Belle, S. R. A. Marque, G. Dorn, F. H. T. Allain, B. Guigliarelli, G. Jeschke, M. Yulikov, The Journal of Physical Chemistry Letters 2017, 4852-4857.

[39] aB. E. Bode, J. Plackmeyer, T. F. Prisner, O. Schiemann, The journal of physical chemistry. A 2008, 112, 5064-5073; bI. Kaminker, I. Tkach, N. Manukovsky, T. Huber, H. Yagi, G. Otting, M. Bennati, D. Goldfarb, Journal of magnetic resonance (San Diego, Calif. : 1997) 2013, 227, 66-71; cJ. E. Lovett, A. M. Bowen, C. R. Timmel, M. W. Jones, J. R. Dilworth, D. Caprotti, S. G. Bell, L. L. Wong, J. Harmer, Physical chemistry chemical physics : PCCP 2009, 11, 6840-6848.

[40] aM. Qi, A. Gross, G. Jeschke, A. Godt, M. Drescher, J Am Chem Soc 2014, 136, 15366-15378; bA. Martorana, G. Bellapadrona, A. Feintuch, E. Di Gregorio, S. Aime, D. Goldfarb, J Am Chem Soc 2014, 136, 13458-13465; cM. Azarkh, A. Bieber, M. Qi, J. W. A. Fischer, M. Yulikov, A. Godt, M. Drescher, The Journal of Physical Chemistry Letters 2019, 10, 1477-1481. 
[41] Y. Yang, F. Yang, X.-Y. Li, X.-C. Su, D. Goldfarb, The Journal of Physical Chemistry B 2019, 123, 1050-1059.

[42] A. Shah, A. Roux, M. Starck, J. A. Mosely, M. Stevens, D. G. Norman, R. I. Hunter, H. El Mkami, G. M. Smith, D. Parker, J. E. Lovett, Inorg Chem 2019, 58, 3015-3025.

[43] G. Prokopiou, M. D. Lee, A. Collauto, E. H. Abdelkader, T Bahrenberg, A. Feintuch, M. Ramirez-Cohen, J. Clayton, J. D. Swarbrick, B. Graham, G. Otting, D. Goldfarb, Inorg. Chem. 2018, 57, 5048-5059.

[44] aY. Yang, F. Yang, Y. J. Gong, J. L. Chen, D. Goldfarb, X. C. Su, Angew Chem Int Ed Engl 2017, 56, 2914-2918; bY. Yang, F. Yang, Y.-J. Gong, T. Bahrenberg, A. Feintuch, X.-C. Su, D Goldfarb, The Journal of Physical Chemistry Letters 2018, 9 , 6119-6123.

[45] aJ. Benesh, T. V. M., R. O. Yu., A. Dmitry, B. E. G., P. T. F., Angew. Chem. Int. Ed. 2016, 55, 11538-11542; bB. Joseph, V. M. Tormyshev, O. Y. Rogozhnikova, D. Akhmetzyanov, E. G. Bagryanskaya, T. F. Prisner, Angewandte Chemie 2016, 128 , $11710-11714$

[46] G. W. Reginsson, N. C. Kunjir, S. T. Sigurdsson, O. Schiemann, Chemistry - A European Journal 2012, 18, 13580-13584.

[47] G. Y. Shevelev, O. A. Krumkacheva, A. A. Lomzov, A. A Kuzhelev, O. Y. Rogozhnikova, D. V. Trukhin, T. I. Troitskaya, V. M. Tormyshev, M. V. Fedin, D. V. Pyshnyi, E. G.

Bagryanskaya, Journal of the American Chemical Society 2014, 136, 9874-9877.

[48] A. A. Bobko, I. Dhimitruka, J. L. Zweier, V. V. Khramtsov, Journal of the American Chemical Society 2007, 129, 72407241.

[49] B. Driesschaert, A. A. Bobko, T. D. Eubank, A. Samouilov, V. V. Khramtsov, J. L. Zweier, Bioorganic \& Medicinal Chemistry Letters 2016, 26, 1742-1744.

[50] J. J. Jassoy, A. Berndhäuser, F. Duthie, S. P. Kühn, G. Hagelueken, O. Schiemann, Angew. Chem. Int. Ed. 2017, 56 , $177-181$.
[51] Z. Yang, M. D. Bridges, C. J. López, O. Y. Rogozhnikova, D. V. Trukhin, E. K. Brooks, V. Tormyshev, H. J. Halpern, W. L. Hubbell, Journal of Magnetic Resonance 2016, 269, 50-54.

[52] aA. Mykhailo, O. Oliver, S. Vijay, S. I. T., H. J. S., D. D. R., D. Malte, ChemBioChem 2011, 12, 1992-1995; bA. Mykhailo, S. Vijay, O. Oliver, D. D. R., H. J. S., D. Malte, Chemphyschem : a European journal of chemical physics and physical chemistry 2012, 13, 1444-1447; cI. Krstic, R. Hansel, O. Romainczyk, J. W. Engels, V. Dotsch, T. F. Prisner, Angew Chem Int Ed Engl 2011, 50, 5070-5074; dJ. Cattani, V. Subramaniam, M. Drescher, PCCP 2017, 19, 18147-18151.

[53] L. John, M. Drescher, Bio-protocol 2018, 8, e2798.

[54] F.-X. Theillet, A. Binolfi, B. Bekei, A. Martorana, H. M. Rose, M. Stuiver, S. Verzini, D. Lorenz, M. van Rossum, D. Goldfarb, P. Selenko, Nature 2016, 530, 45-50.

[55] E. Di Gregorio, G. Ferrauto, E. Gianolio, S. Aime, Contrast Media \& Molecular Imaging 2013, 8, 475-486.

[56] aM. J. Schmidt, J. Borbas, M. Drescher, D. Summerer, J Am Chem Soc 2014, 136, 1238-1241; bT. Braun, M. Drescher, D. Summerer, International journal of molecular sciences $\mathbf{2 0 1 9}$, 20; cW. Wan, J. M. Tharp, W. R. Liu, Biochim. Biophys. Acta 2014, 1844, 1059-1070; dC. H. Kim, J. Y. Axup, P. G. Schultz, Curr. Opin. Chem. Biol. 2013, 17, 412-419.

[57] M. J. Schmidt, A. Fedoseev, D. Bücker, J. Borbas, C. Peter, M. Drescher, D. Summerer, ACS Chemical Biology 2015, 10, 2764 2771.

[58] F. C. Mascali, H. Y. Ching, R. M. Rasia, S. Un, L. C. Tabares, Angew Chem Int Ed Engl 2016, 55, 11041-11043.

[59] aB. Joseph, A. Sikora, E. Bordignon, G. Jeschke, D. S. Cafiso, T. F. Prisner, Angew Chem Int Ed Engl 2015, 54, 6196-6199; bB. Joseph, A. Sikora, D. S. Cafiso, Journal of the American Chemical Society 2016, 138, 1844-1847.

[60] X. Jiang, M. A. Payne, Z. Cao, S. B. Foster, J. B. Feix, S. M. C. Newton, P. E. Klebba, Science 1997, 276, 1261-1264. 


\section{MINIREVIEW}

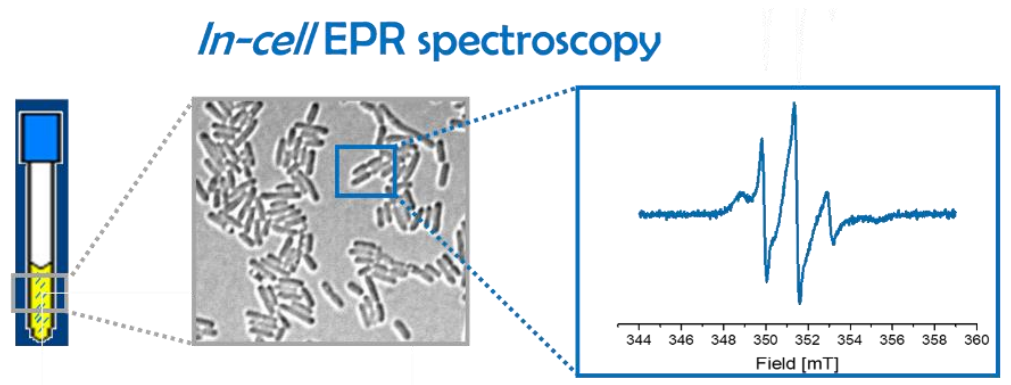

Among magnetic resonances approaches, Site-Directed Spin Labeling (SDSL) coupled to Electron Paramagnetic Resonance (EPR) spectroscopy exhibits competitive and advantageous features to capture protein structure and dynamics inside cells. To date, several in-cell EPR approaches have been successfully applied to both bacterial and eukaryotic cells. In this review, the major advances of in-cell EPR are summarized, as well as the challenges this approach still holds.
Alessio Bonucci, Olivier Ouari, Bruno Guigliarelli, Valérie Belle and Elisabetta Mileo*

Page No. - Page No.

In-cell EPR: progress towards structural studies inside cells. 